\title{
ESQUISTOSSOMOSE MANSÔNICA: A PROPOSITO DA ALTA PREDO- MINANCIA DAS FORMAS INTESTINAIS EM UMA LOCALIDADE DO ESTADO DE PERNAMBUCO
}

\author{
Ruy João Marques **, Dirceu Pessoa Costa ***, Mauro W. Siqueira *** \\ e Geraldo José M. Pereira $* \star \star \star *$
}

\begin{abstract}
Considerando que a Esquistossomose Mansônica é geralmente considerada doença de mau prognóstito, os Autores lembram que esta noçāo é fruto do contacto exclusivo, por parte dos médicos, com casos avançados $e$ graves, praticamente os unicos que vêm ter aos hospitais das grandes cidades.

Ressaltando que estágios ou pesquisas em zonas endêmicas dão, aos interessados pelo assunto, uma visão mais exata da morbidade da parasitose, eles reproduzem seus achados em 220 esquistossomóticos de uma localidade (Tiúma) do Municipio de São Lourenço da Mata, Pernambuco: 90\% de formas intestinais (muitas vezes assintomáticas), 7,7\% de formas hépato-intestinais e 2,3\% de formas hépato-espleno-intestinais. Nenhuma forma descompensada com hematêmese, ascite ou coma hepático foi assinalada.

Aproveitando a circunstância, foram recordadas as possiveis causas determinantes das formas clínicas e da evolução da Esquistossomose Mansônica, acreditando os Autores serem duas as de maior importância : a carga parasitária e as reaçôes imunológicas.
\end{abstract}

\section{INTRODUÇÃO}

A Esquistossomose Mansônica é, ordinariamente, considerada doença de sombria evolução. Compêndios de Clínica Médica (5) e de Medicina. Tropical (23) contribuem, não raro, para isso, pois dão, em certos casos, demasiada ênfase às formas graves da moléstia. Por outro lado profissionais que, longe dos focos da parasitose, recebem apenas esquistossomóticos com hipertensão porta bem evoluída nas suas enfermarias, deixam-se influenciar pelo fato e costumam ficar imbuídos da falsa idéia referente a um invariável ou quase invariável mau prognóstico.

Por outro lado, a imprensa leiga - cada vez mais sensacionalista - divulga, todos os dias, estas distorcidas imagens, atemorizando os leitores que, compreensivelmente alarmados, procuram seus médicos à menor suspeita da doença em questão.

O estudioso do assunto, sobretudo aquele que se fixou em área endêmica ou que para ela se desloca a fim de realizar determinadas pesquisas chega, entretanto, fa-

* Trabalho realizado no Centro de Pesquisa Aggeu Magalhães (INERu) e no Departamento de Medicina. Tropical da F.M.U.F.Pe. - Recife, Brasil.

* Chefe do Departamento de Med. Tropical (F.M.U.F.Pe.)

*** Diretor do Centro de Pesquisa Aggeu Magalhães (INERu)

**** Prof. Asstst. do Dept. de Med. Tropical (F.M.U.F.Pe.)

**** Auxiliar de Ensino do Dept. Med. /Troplcal (F.M.U.F.Pe.)

Recebido para publicação em 15-8-1974. 
cilmente, à evidência de que a Esquistossomose Mansônica é, muito pelo contrário, na maioria dos casos, doença bem tolerada pelos pacientes.

A idéia - tão difundida - de que praticamente todos os casos da referida parasitose são graves ou, ao menos, potencialmente graves, precisa, a bem da verdade, ser modificada.

Esta nossa conviç̧ão vem cada vez mais se robustecendo à medida que estendemos nossas investigações a certas áreas consideradas ora endêmicas ora hiperendêmicas do interior do Estado de Pernambuco e é precisamente parte dos resultados que vamos obtendo em tais estudos que pretendemos aqui comentar.

Antes, porém, de expor nossos dados, cumpre salientar que tal ponto de vista é também esposado por alguns autores da maior responsabilidade. Freitas (17), por exemplo, salienta que, na maioria das vezes, as formas clínicas são "aparentemente assiotomáticas"; Barroso (4), revendo 883 marinheiros, chegou à evidência de que nenhum deles apresentava "forma grave da moléstia"; e Ruas (30) informa que na área do Colonato do Limpopo, em Moçambique, onde trabalhou, a hipertensão porta esquistossomótica é relativamente rara. Em favor deste ponto de vista vale salientar ampla pesquisa realizada por Barbosa (3) em quatro localidades do Estado de Pernambuco, situadas no litoral e nas zonas fisiográficas denominadas "mata seca" e "mata úmida" (Muribeca, Pontezinha, Macujê e Agua Preta) através da qual pôde concluir que ali "a esquistossomose se apresenta em condiçōes naturais como endemia que, embora com alguma proporção de casos graves, evolui na maioria das pessoas infectadas com pequena ou nenhuma repercussão clínica; nos seus casos "as grandes formas descompensadas da esquistossomose nunca foram encontradas".

Também Pessoa e Amorim (27), estudando a "gravidade" da Esquistossomose em algumas localidades (Gulandim, Pilar e Atalaia) de Alagoas encontraram entre $\mathbf{8 8 , 4 \%}$ e $\mathbf{9 0 , 7 \%}$ de "tipos benígnos" e de $\mathbf{9 , 2 \%}$ a $\mathbf{1 3 , 6 \%}$ de "tipos graves".

\section{MATERIAL E METODOS}

Nossa casuística para o presente trabalho é constituída de 220 habitantes da localidade de Tiúma, do Município de São Lourenço da Mata, no Estado de Pernambuco e distando 20 quilômetros da cidade do Recife. zona açucareira (plantação e indústria) considerada como altamente endêmica. O hospedeiro intermediário ali encontrado, com exclusividade, é a Biomphalaria straminea.

São Lourenço acha-se banhado pelo rio Capibaribe, cujos afluentes são freqüentados pela grande maioria das pessoas que ali residem, ora para simples folguedos, como acontece com as crianças e os adolescentes, ora para "higiene" corporal no fim de um dia de atividade, ora ainda para trabalho, tal como ocorre com as lavadeiras, com os pescadores e com os lavadores de animais ou de carros.

A maior parte dos nossos observados e constituída de operários da Usina Tiúma ou seus familiares, ocupando faixas etárias que vão de 10 a 65 anos e de ambos os sexos, como se vê nos Quadros I e III. Ao todo foram examinados 220 esquistossomóticos.

QUADRO I

NÚMERO DE PACIENTES POR GRUPO ETARIO

\begin{tabular}{r|c|c}
\hline $\begin{array}{c}\text { IDADE } \\
\text { (anos) }\end{array}$ & $\begin{array}{c}\text { NUMEROS DE } \\
\text { PACIENTES }\end{array}$ & $\%$ \\
\hline $0-10$ & 14 & 6,36 \\
$11-20$ & 93 & 42.28 \\
$21-30$ & 45 & 20.46 \\
$31-40$ & 36 & 16.36 \\
$41-50$ & 25 & 11.36 \\
$51-60$ & 7 & 3.18 \\
$61-70$ & 0 & 0 \\
& & \\
\hline TOTAL & 2,20 & \\
\hline
\end{tabular}

o nivel sanitário mostra-se, ali, lamentavelmente baixo; a despeito da existência de fossas em certo número de habitaçōes é muito disseminado o costume de fazer dejeçōes nos criadouros próximos às casas. A água de beber é obtida de cacimbas ou dos próprios riachos $\mathrm{e} o$ hábito de andar descalço é - particularmente entre as crianças - ainda bastante comum entre os residentes da zona rural do Município onde realizamos a investigação. 
Exames parasitolãgicos de fezes foram realizados no Centro de Pesquisa Aggeu Magalhães do INERu, em 2000 habitantes da Vila, 32\% dos quais resultaram positivos para ovos de Schistosoma mansoni.

o material coletado em frascos com tampa de polietileno contendo $10 \mathrm{mil}$ de "Solução Mifc" era utilizado para contagem quantitativa pelo método de $\boldsymbol{F}$. Simões Barbosa.

Os casos positivos submetiam-se a exame realizado no ambulatório da Usina Tiúma, por médicos do Departamento de Medicina Tropical da F.M.U.F.Pe. que se encarregavam também de preencher cuidadosamento um questionário contendo informações acerca da casa de cada um deles, dos seus co-habitantes, do tempo de permanência na localidade, das residências anteriores, das condições sanitárias da família, do tipo de coleção dágua freqüentado, da hcra e da duração dos contactos com o foco suspeito e de vários outros dados importantes aproveitados para diferentes estudos epidemiológicos e clínicos paralelos.

As formas das moléstias apresentadas pelo; paciontes eram registradas obedecendo à seguinte classificação: a) assintomática (positividade do exame de fezes sem qualquer sintoma ou sinal); b) intestinal (presença de diarréia, constipação, dores no colon ou outra manifestação atribuível à esquistossomose); c) hépato-intestinal (distúrbios do rítmo e dores intestinais + palpabilidade hepática); d) hépato-espleno-intestinal; e) hépato-esplênica.

\section{QUADRO II}

\section{DISTRIBUIÇÃO DAS FORMAS CLINICAS DA ESQUISTCSSOMOSE MANSÔNICA EM 220 PACIENTES}

\begin{tabular}{l|r|r} 
& \multicolumn{2}{|c|}{ Pacientes examinados } \\
\cline { 2 - 3 } Formas Clinicas & n.o & $\%$ \\
\hline $\begin{array}{l}\text { Intestina! } \\
\text { Hépato-intestinal } \\
\text {-intestina! }\end{array}$ & 198 & 90.0 \\
& 17 & 7.7 \\
& 5 & 2.3
\end{tabular}

Obs.: - Dos $220,113(51,36 \%)$ eram as intomáticos.
Além do exame físico de cada paciente e da já aludida coproscopia realizavam-se sistematicamente provas laboratoriais complementares de diferente natureza, algumas das quais serviram a pesquisas paralelas, bem como para avaliação do risco de uma terapêutica anti-esquistossomótica a que se submeteu a maioria dos observados (material destinado a outra publicação).

\section{RESULTADOS E COMENTARIOS}

Através da história relatada pelos pacientes e dos exames clínicos neles realizados foi possivel obter os seguinties dados, resumidos nos Quadros I, II e III para meIhor compreensão.

Fatos bastante interessantes podem ser constatados através a apreciação dos Quadros; no presente trabalho, porém, desejamos deter-nos apenas em um deles: a gritante predominância das formas intestinais $(90 \%)$ em relação às hépato-intestinais $(7,7 \%)$ e sobretudo às hépato-espleno-intestinais $(2,3 \%)$.

Com efeito em uma zona considerada hiperendêmica, com altíssima prevalência $(80-90 \%)$, onde não se ensaiou qualquer providência profilática e onde as condições sócio-econômicas - aqui incluído o aspecto nutricional da população - se mostram muitíssimo aquem do ideal, poder-se-ia esperar resultados assaz diferentes a concluir pelo que em certas esferas se julga; uma incidência bem maior daqueles casos que se convencionou chamar graves seria licito esperar.

Muito pelo contrário, de acordo com o que observamos são praticamente inexistentes, na área por nós explorada, as formas hépato-esplênicas; ainda mais: entre os doentes passados pelas nossas mãos as hemorragias digestivas, a ascite e o coma hepático, isto é, as chamadas descompensações, não foram registradas.

Esta observação pôde ser, aliás, confirmada através de contato com médicos radicados no Município de São Lourenço da Mata que informaram constituir raridade, nas suas clínizas, as formas mais sćrias da parasitose em apreço; conforme declaraçõos textuais, eles, como nóz, encontraram preferencialmonte a forma intestinal, muitas vezes assintomática.

Cs resultados por nós obtidos necte particular merecem ser divulgados sobretudo 
QUADRO III

\begin{tabular}{c|c|cc|cr|rr}
\hline $\begin{array}{c}\text { Grupos etários } \\
\text { (anos) }\end{array}$ & $\begin{array}{c}\text { Total de } \\
\text { examina- } \\
\text { dos }\end{array}$ & Forma intestinal & $\begin{array}{c}\text { Forma hépato- } \\
\text { intestinal }\end{array}$ & $\begin{array}{c}\text { Formas hépato- } \\
\text { espleno-intestinal }\end{array}$ \\
\hline & N.o & N.o & $\%$ & N.o & $\%$ & N.o & $\%$ \\
Total & 220 & 198 & 90 & 17 & 7,7 & 5 & 2,3 \\
& & & & & & & \\
\hline & 14 & 12 & 85.71 & 1 & 7.14 & 1 & 7.14 \\
$0-10$ & 93 & 83 & 89.24 & 9 & 9.67 & 1 & 1.07 \\
$11-20$ & 45 & 43 & 95.55 & 1 & 2.22 & 1 & 2.22 \\
$21-30$ & 36 & 33 & 91.66 & 1 & 2.77 & 2 & 5.55 \\
$31-40$ & 25 & 22 & 88.00 & 3 & 12.00 & 9 & 0.00 \\
$41-50$ & 7 & 5 & 71.42 & 2 & 28.57 & 9 & 0.00 \\
$51-60$ & 0 & 0 & 0.00 & 0 & 0.00 & 9 & 0.00 \\
$61-70$ & & & & & & & \\
\hline
\end{tabular}

entre os médicos que, residindo nas capitais, se acostumam a receber do interior apenas casos avançados e graves da Esquistossomose Mansônica.

Por outro lado, vale apreciá-los em maior profundidade, buscando-se, através do que nos foi dado observar, alguma contribuição ao esclarecimento de um problema que preocupa não poucos pesquisadores: o do estabelecimento das formas clínicas de tão disseminada parasitose.

Várias são as causas apontadas como capazes de determinar, direta ou indiretamente, a evolução de um caso de esquistossomose, ou, ao menos, capazes de contribuir para o estabelecimento de tal ou qual forma clínica ou anatomo-clínica da helmintose em questão. Algumas parecem de maior, outras de menor importância; umas \&ão facilmente aceitáveis, outras, talvez um tanto fantasiosas ou, ao menos, ainda desprovidas de bases científicas perfeitamente estabelecidas.

Neste último caso, encontra-se, por exemplo, a hipótese que procura explicar a diversidade de formas clínicas através da variedade de cepas do Schistosoma mansoni, umas teoricamente mais e outras menos patogênicas.

Hipótese também ainda não estabelecida de modo rigorosamente aceitável é aquela referente à influência racial, ou talvez, à simples cor da pele. A forma hépato-esplênica seria mais rara nos doentes de cor negra, embora não haja explicação plausivel para o fato. Cheever (6), tratando do assunto, diz não poder explicar por que a fibrose de Symmers parece ser menos freqüente nos pretos embora lembre a possibilidade destes desenvolverem uma melhor imunidade.

Mais fácil se nos afigura explicar a influência de outros fatores.

As associaçōes mórbidas, por exemplo, devem influir desfavoravelmente sobre a evolução da esquistossomose, sobretudo se a moléstia ajuntada lesa o hepatócito ou, de qualquer outro modo, compromete o fígado e a circulação porta. evidente que, entre outras, a malária, as hepatites e o calazar - passiveis de serem endêmicos em áreas esquistossomóticas - estão neste caso. Um de nós (25) acompanhou interessante caso de leishmaniose visceral no qual o tratamento com Glucanthime fez regredir totalmente o baço mas, ao contrário do que em geral ocorre, não totalmente o figado; tratava-se de um caso de associação com esquistossomose e certamente a hepatomegalia em parte estava ligada a esta última parasitose, sabidamente não sensível aos antimoniais pentavalentes. Não nos foi possível infelizmente acompanhar, por muito tempo, o paciente, mas julgamos que a evolução não fol grave, pois doutro modo ele teria voltado à Clínica de Doenças Tropicais onde estivera internado.

O alcoolismo é também associação capaz de contribuir para alterar a evolução 
da esquistossomose, como, de resto, todas as condiçôes relacionadas com a nutrição do indivíduo.

O assunto - esquistossomose e nutriçāo - tem aliás, inspirado numerosos trabalhos de DeWitt e colab. $(13,14,15,16)$, E. Coutinho Abath e colab. $(11,12)$ e outros.

f justo admitir que um estado carencial de grande e média intensidade - sobretudo no setor proteico e vitamínico repercuta tanto nos mecanismos gerais de defesa do organismo quanto no fígado propriamente dito e possa, desta maneira, modificar as reações à penetração das cercárias e à presença de ovos e vermes neste ou naquele órgão.

Muito mais amplamente aceito - como elemento decisivo no estabelecimento das diversas formas clínicas da Esquistossomose - é a chamada carga parasitária.

f, aliás, teoricamente bastante lógico admitir que quanto maior o número de cercárias, penetradas no hospedeiro, isto é, quanto mais intensa a infestação, tanto mais grave o processo mórbido nele despertado.

Daí a importância da freqüência com que $o$ indivíduo visita o foco, da proximidade do mesmo em relação à sua casa facilitando ou dificultando os contatos -, do horário e duração das exposiçōes, etc. Daí também a relevância daquilo que Barbosa e Coelho $(1,2)$ chamam "qualidades do hospedeiro intermediário" existente na área, pois se algumas espécies são consideradas excelentes, outras são simplesmente boas e até más, como transmissoras.

Sem desprezar, de modo algum, o papel desempenhado pela carga parasitária, cumpre aqui salientar a importância que cada vez mais assume o fator imunológico na evolução e no estabelecimento das diversas formas clínicas da Erquistossomose. Multiplicam-se as contribuições estrangeiras $(8,9,21,31,32,33,34,35)$ e nacionais $(19,20,22)$ sobre o assunto, todas chegando a conclusões muito favoráveis acerca da importância da resposta do hospedeiro à parasitose na determinação das formas graves.

Eis, por exemplo, o que escrevia, já em 1963, Kenneth S. Warren (33) como conclusão de rigorosa pesquisa: "este estudo indica que a esquistossomose mansônica hépato-esplênica ocorrerá $\mathrm{\epsilon m}$ ratos com uma carga minima de ovos, que existe uma relação entre o tempo de aparecimento do sindromo e o número de vermes presentes e que, embora o fator parasitário básico na produção deste síndromo pareça ser o ovo, a resposta do hospedeiro também goza um papel importante na sua patogenia". Eis, também, o que escreveram, recentemente, como uma das conclusōes de trabalho realizado com macacos Rhesus, Cheever e Powers (7): "a reIação entre carga parasitária e o número de ovos nas fezes é consideravelmente influenciada pela resposta do hospedeiro".

Em conferência pronunciada em 1961, no XIII Congresso Brasildeiro de Gastro-enterologia e no Simpósio sobre "Esquistossomose e Fígado", da II Jornada Nacional de Hepatologia (1972) um de nós (24, 26) defendeu estes dois fatores como os principais no desencadeamento de tal ou qual sintomatologia da infestação esquistossomótica.

Da posse do material que serviu para o presente trabalho esta nossa convicção se robusteceu.

Apesar da hiperendemicidade da área estudada, a carga parasitária dos nossos 220 observados pareceu-nos sempre pequena, pois o número médio de ovos contados por grama de fezes através do método de Barbosa foi de 4,2 (o menor de 1 e o maior de 36), o indice de ratos silvestre naturalmente infectados na localidade é praticamente nulo segundo investigação realizada, anos atrás, por um de nós (10) e o hospedeiro intermediário ali encontrado com exclusividade - é a Biomphalaria straminea. Este planorbídeo, estimado por Lucena (18) como o de maior importância epidemiológica no Nordeste do Brasil pela sua considerável di:seminação $(83,48 \%$ das localidacies endêmicas) é considerado por Barbosa e Coelho (2), "sob o ponto de vista biclógico, mau vetor, condic'onando índices cercários baixos, com taxas de infestaçāo insignificantes, com pequeno período de eliminação de cercárias".

Pela soma destes fatos é lícito acreditar na pequena carga parasitária apresentada pelos nossos observados.

Por outro lado, apear de submetidos às mesmas condições epidemiológicas, alguns dos nossos doentes - poucos, é bem verdade, como já salientamos - apr-sentavam hepatomegalia e - pouquíssimos hépato-esplenomegalia, o que demonstra haver em jogo, além do elemento carga 
parasitária, outro fator que é lícito admitir ser de natureza imunológica.

* Sejam, porém, quais forem as verdadeiras determinantes das formas clínicas da Esquistossomose Mansônica, o que nos propusemos a aqui salientar foi a imensa freqüência de casos com sintomatologia discreta ou nula entre os nossos observados.

Cumpre-nos, concluindo, estimular pesquisas idênticas em áreas outras, também endêmicas, do território nacional, incluindo compl`mentarmente investigaçōes sobre a esquistossomose como causa de morte.
Esta última tarefa se nos afigura da maior importância, embora seja fácil prever os óbices que encontrará o investigador interessado no assunto, a começar pelas falhas - ainda que freqüentíssimas - na comprovação de causas de óbito no interior de muitos Estados do Brasil e pelas semelhanças clínicas entre as fases finais das cirroses e as da esquistossomose hépato-esplênica de que poderá resultar - nos centros médicos de pequeno desenvolvimento - em lamentáveis equívocos.

\section{$S U M M A R Y$}

Although Schistosomiacis mansoni is generally considered as a disease of sevore prognos's, the AA attributed this notion to the fact that doctors living in big cities, farway from the endemic regions, are used to see not more than very advanced and serious cases, the only ones which come to their hospitals.

Enphasizing that visits to or researches on the areas of endemicity give to the dostors a more exact idea of the morbidity of the parasitosis, they present the result of a parasitological and clinical study performed in a small village (Tiuma) of São Lourenço da Mata, State of Pernambuco, Brazil; 90\% of patients with intestinal form (many assymptomatic cases), 7,7\% with the hepato-intestinal form, and 2,3\% with the hepato-spleno-intestinal form of the disease. No one of the 220 patients had digestive hemorrhage, ascites or hepatic coma during the period of observation.

$A$ review of the possible causes of variations in the evolution of the infection $b y$ Schistosoma mansoni was made. The AA admit that the heaviness of the infection (worm burden) and the immunological conditions of each patient are the most important ones.

\section{REFERENCIAS BIBLIOGRAFICAS}

1 - BARBOSA, F.S. \& COELHO, M.V. - Qualidades de vetor dos hospedeiros de $S$. mansoni no Nordeste do Brasil, I - Suscepitibilidade de $A$. glabratus e $T$. centimetralis à infestaçao por $S$. mansoni. Publ. Avulsas Inst. Aggeu Magalhães III: 55-62, 1954.

2 - BARBOSA, F.S. \& COELHO, M.V. - Alguns aspectos epıdemiológicos relacionados com a transmissão da esquistozsomose em Pernambuco. Brasil. Publ. Av. do Centro Pesq. Aggeu Magalhães $V: 31-47,1956$.

3 - BARBOSA, F.A.S. - Morbidade na Esquistossomose. Estudo em quatro localidades no Estado de Pernambuco. Tese. Recife, 1965.

4 - BARRoso, G. - Como evolue a esquistossomose nos marinheiros da M. de Guerra (Resposta). II Simpósio sobre Esquistossomose. Ed. Ministério Marinha, 141-142, Salvador, 1970.

5 - CECIL, R.L. - Tratado de Medicina (Trad. $7^{\text {a }}$ ed.) -2 tomos. Ed. Guanabara, Ris de Janeiro, 1949.

6 - CHEFver, A.W. - Porque uns doentes de Esquistossomose apresentam formas graves e outros não (Resposta). II Simpósio sobre Esquistossomoze. Ed. Ministério Marinha, 98-99, Salvador, 1970.

7 - CHEEVER, A.W. \& POWERS K.G. - Schistosoma mansoni infection in Rhesus monkey: comparison of the course of heavy and light infections - Bulletin of the World Health Organization (Geneve) XLVI, 3, 301$309,1972$. 
8 - COLLEY, D D., MAGALHÃES F. ${ }^{\circ}$, \& COELHO, B. R. - Immunopathology of Dermal Reactions induced by Schistosoma mansoni cercariae and cercarial extract. Am ${ }^{\circ} \mathrm{J}$. Trop. Med. Hyg. 21: 5558-568. 1972.

9 - COOK, J.A., WOODSTOCK, L \& JORDAN, P. - Immunological studies in Schistosoma mansoni infection in St. Lucia. Annals of Tropical Medicine and Parasitology LXVI, $369-374,1972$.

10 - CosTA, D.F. - Relatório de Plano Piloto - Esquistossomose - Centro de Pesq. Aggeu Magalhães - Recife, 1972 .

11 - COUTINHO ABATH, E. - Esquistossomo:e mansonica e nutricão. Rev. Bras. Malariol. Doencas Trop. 16: 233-253, abril-junho, 1964.

12 - COUTINHO ABATH, E., ESPIRITO SANTO, M., BARBOSA, J.M. \& MELO, S.A. - Padráo alimentar em áreas endêmicas de E.M. no Nordeste brasileiro. Rev. Bras. Malariol. Doenças Tropicais 16: 555-589, 1964.

13 - DEWITT, W.B. - Effects of Schistosoma mansoni infections on the ab lity of mice to digest and absorb dietary fats and proteins. - J. of Parasit, 43: 32, 1957.

14 - DEWITT, W.B. - Fxperimental Schistoscmiasis Mansoni in micemaintained on nutritionally deficient diets. I Effects of a Torulx Yeast diet deficient in factor 3 , Vitamin $\mathbf{E}$ and cystine. $\mathbf{J}$. of Parasit. 43: 119-128, 1957.

15 - DEWITT, W.B. - Experimental Schistoromiasis mansoni in mice maintained on nutritionally deficient diets. II Survival and development of Schistosoma mansoni in mice maintained on a Torula yeast diet deficient in factor 3 , vitamin $E$ and cystine. $y$. of Parasit, 43: 129-315, 1957.

16 - DEWITT, W.B., OLIVER - GONZALEZ,J. \& MEDINA, E. - Effects of improving the nutrition of malnourisher people infected with Schistosoma mansoni. Am. J. Trop. Med. Hyg. 13: 25-35, 1964.

17 - FREITAS, C.A. - Estimativa da popularão esçuisto:somótica no Brasil (Respo:ta) II Simpósio sobre Esquistossomose. Ed. Ministério Marinha, 77-78 - Salvador, 1970.

18 - LUCENA, D.T. - Planorbideos transmissores da Esquistossomose no Nor- deste do Brasil. Rev. Bras. Malariol. D. Trop. 15: 13-25, 1963 .

19 - MAGALHÃES F.', A. - Pulmonary lesions in mice experimentally infected with Schistosoma mansoni. Am. J. Trop. Med. Hyg. 7: 527-535, 1959.

20 - MAGALHÃES F. ${ }^{\circ}$, A. - Reações de hipersensibilidade em Macacos Cebus infestados com Schistosoma mansoni. Rev. Inst. Med. Tropical São Paulo, 31: $239-253,1951$.

21 - MAGALHÃES F.o, A.. KRUPP, I.M. \& MALEK, E. Localization of antigen and presence of antibody in tissue of mice infected with Srhistosoma mansoni, as indicated by fluorescent antibody technics. Am. $\mathbf{J}$. Trop. Med. Hyg., 14: 84-99, 1965.

22 - MAGALHăES F.o, A., E. COELHO, R. \& VOSS, H. - Hipersensibilidade mansônica. . Rev. Latino-Am rricana de Microb. y Parasit. 8: 2J7-214, Out-Nov., 1966.

23 - MANSGN-BAHR, P.H. - Synopsis of Tropical Medicine - Casell and Company, Ltd, Londres, 1952.

24 - MARQUES, R.J. - Formas clinicas da Esquistossomose mansônica: condições determinantes. Cooferência no XIII Congr. Brasileiro de Gastroenterologia, Recife - Julho, 1961

25 - MARQIJES, R.J., LUCENA, D.T. \& SARAIVA, A. - Leishmaniose visceral em Pernambuco (a propósito de dois novos casos). J. Bras. Medicina, 11: 139-153, 1963.

26 - MARQUES, R.J. - Aspecto 3 clínicos da hepatopatia esquictosomólina II Jornada Nacional de Hepatologia, Recife, 1973.

27 - PESSOA. S.B. \& AMORIM, J.P. Notas sobre a Esquistossomose Mansônica em algumas losalidades de Alagoas. Rev. Br. Med. 14: 6, 1957.

28 PESSOA. S. \& MARTINS, A.V. - Paracitologia Médica - Ed. Guanabara Koogan, 9a Ed., 1974.

29 - POWFRs. K.G. \& CHF,FTEr A.W. - Comparison of Geographical strains of Sch. mansoni in the rhesus monkey - Bulletin World Health Organization (Geneve) 4j: 245-300, 1972.

30 - RUAS, A. - Resultados obtidos no seguimento dos doentes com ripert. porta esquistossomótica submatidos à anastomose porto-cava. (Resposta) II Simnó io sobre Espuistossomose Ed. Ministério Marinha, 154-155, Salvador, 1970. 
31 - VON LICHTENBERG, F. - Discussion of the paper by Keneth $\mathbf{S}$. Warren: "Pathophysiology and $\mathrm{Pa}$ thogenesis of Hepato-splenic Schistosomiasis Mansoni" - Symposia in Clinical Tropical Medicine - Vol. I, 66-71 N.Y. Academy of Medicine, Ed. K. M. Cahill, New York, 1972.

32 - WARREN, K.S. - The etiology of hepato-splenic schistosomiasis mansoni in mice - Am. J. Trop. Med. Hyg. 10: 870-876, 1961.

33 - WARREN, K.S. - The contribution of worm burden and host response to the development of hepato-splenic schistosomiasis mansoni in mice. Am. J. T'rop. Med. Hyg. 12: 34-39, 1963.

34 - WARREN, K.S. - The immunopathogenesis of schistosomiasis: a multidisciplinary approach. - Trans. Roy Soc. Trop. Med. Hyg.,46: 347$-432,1972$.

35 - WARREN, K.S. - Pathophysiology and Pathogenesis of Hepatosplenic Schistosomiasis Mansoni - Symposia in Clinical Tropical Medicine, Vol. I, 51-65 - N. Y. Academy of Medicine. Ed. K.M. Cahill, New York, 1972. 